\title{
Study on mesosphere summer echoes observed by digital ionosonde at Zhongshan Station, Antarctica
}

\author{
Hai-Long $\mathrm{Li}^{1}$, Jian $\mathrm{Wu}^{2}$, Rui-Yuan $\mathrm{Liu}^{3}$, and Ji-Ying Huang ${ }^{1}$ \\ ${ }^{1}$ School of Science, Xidian University, Xi' an 710071, P. R. China \\ ${ }^{2}$ National Key Laboratory of Electromagnetic Environment, China Research Institute of Radiowave Propagation, \\ Beijing 102206, P. R. China \\ ${ }^{3}$ Polar Research Institute of China, Shanghai 200129, P. R. China
}

(Received February 8, 2007; Revised August 15, 2007; Accepted August 15, 2007; Online published October 19, 2007)

\begin{abstract}
The irregular characteristics of E and Es layers are studied with data from 1995 to 2002 observed by a Digisonde Portable Sounder-4 (DPS-4) ionosonde at Zhongshan Station, Antarctica. Because they have much similar characteristics with Polar Mesosphere Summer Echoes (PMSE), two criteria are proposed to study PMSE at MF and HF bands in Southern hemisphere. The phenomena of irregular E and Es layer are called as PMSElike or Polar Mesosphere Summer Echoes-Es (PMSE-Es) here. The occurrence rate variations of PMSE-Es show similarity to those of PMSE at multi-scales, such as seasonal, diurnal, and semidiurnal variation. Finally, the discrepancies between diurnal, semidiurnal and seasonal variation between PMSE and PMSE-Es are discussed respectively.
\end{abstract}

Key words: Ionogram, Polar Mesosphere Summer Echoes (PMSE).

\section{Introduction}

Polar mesosphere summer echoes (PMSE) are abnormally strong radar returns that occur during summer months near the mesopause at high latitudes (Ecklund and Balsley, 1981). Since then, PMSE have been observed at a variety of frequency bands between the range from MF/HF (Karashtin et al., 1997; Tereshchenko et al., 2002; Ogawa et al., 2002; Ogawa et al., 2003; Hosokawa et al., 2004; Hosokawa et al., 2005) to UHF bands (Cho and Kelly, 1992), especially at VHF and UHF bands. Based on new experimental results from in situ observations with sounding rockets, ground based observations with radars and lidars, numerical simulations with microphysical models of the life cycle of mesospheric aerosol particles, and theoretical considerations regarding the diffusivity of electrons in the ice loaded complex plasma of the mesopause region, an ideal explanation for the generation of these radar echoes has been developed. Some key parameters like temperature, electronic density, dust density, dimensions, and dust charges are detected and used to explain PMSE. Though several theories have been developed for explaining the phenomena, a perfect explanation still are not put forward up to now (Rapp and Lübken, 2004).

By comparing the results observed at HF band with those at VHF band, one finds that PMSE can be detected in the HF range by simultaneous observations with VHF and HF radars. Recently PMSE are observed at Syowa Station, Antarctica (Ogawa et al., 2003) by using HF radar too. Now the experimental researches at HF band have gained

Copyright (c) The Society of Geomagnetism and Earth, Planetary and Space Sciences (SGEPSS); The Seismological Society of Japan; The Volcanological Society of Japan; The Geodetic Society of Japan; The Japanese Society for Planetary Sciences; TERRAPUB much attention. The dynasonde still plays an important role in studying ionosphere phenomena and has the ability to detect PMSE at HF/MF bands (Liu et al., 2002; Lee et al., 2001). Ionosphere has been observed by dynasonde for so long time all over the world that the long-term variation of PMSE properties can be studied.

In the paper, data obtained from February 1995 to December 2002 by DPS-4 at Zhongshan Station in Antarctica (Liu et al., 1997) are used to study PMSE. Based on irregular variations of $\mathrm{E}$ and Es layers, two criteria how to identify PMSE-Es are proposed. With these criteria, seasonal, diurnal and semidiurnal variation of PMSE-Es occurrence rates can be studied and summarized. On the basis of comparisons between PMSE-Es variations in Antarctica and PMSE variations in Arctic, some discrepancies are indicated. Finally, the differences of seasonal variation between the Northern and Southern Hemisphere are also illustrated.

\section{The Criteria of PMSE-Es at Zhongshan Sta- tion, Antarctica}

A general description of the DPS-4 at Zhongshan Station in Antarctica and a summary of initial observations have been given by Liu et al. (Liu et al., 1997). The specifications of this kind of DPS-4 are given in Table 1. Zhongshan Station is situated under the ionospheric projection of the magnetospheric cusp region at noon, and in the polar cap region at midnight. The local time at Zhongshan Station is 5 hour plus the universal time, and the magnetic local time is about 2 hour plus the universal time. The data used in the paper are provided in the form of monthly reportable table, the data are recorded once an hour. Time resolution of the data is not very high.

The ionogram is a record of ionospheric conditions in- 
Table 1. Main characteristics of the DPS-4 used at Zhongshan Station, Antarctica.

\begin{tabular}{ll} 
Station name & Zhongshan \\
Geographic coordinates & $69^{\circ} 22^{\prime} 24^{\prime \prime} \mathrm{S}, 76^{\circ} 22^{\prime} 40^{\prime \prime} \mathrm{E}$ \\
Geomagnetic coordinates & $77.1^{\circ} \mathrm{S}, 121.3^{\circ} \mathrm{E}$ \\
Invariant latitude & $74.5^{\circ}$ \\
Time used & $75^{\circ} \mathrm{E}(\mathrm{LT}=\mathrm{UT}+5$ hours $)$ \\
Ionosonde equipment type & $\mathrm{DPS}-4($ digital $)$ \\
Frequency range & $1-40 \mathrm{MHz}$ (in $100 \mathrm{kHz}$ steps $)$ \\
Bandwidth at 6 dB points & $20 \mathrm{kHz}$ (minimum pulse width: $66.7 \mu \mathrm{s})$ \\
Receive antenna configuration & 4 active crossed loops \\
Receive antenna polarization & Right and left circular polarization \\
Transmit antenna configuration & Delta antenna \\
Transmit antenna output impedance & $50 \Omega$ \\
Output power & $500 \mathrm{~W}$ in pulse, $250 \mathrm{~W}$ per antenna \\
Pulse repetition frequency & 50,100 or 200 pulse/sec \\
Range accuracy & $2.5 \mathrm{~km}, 5 \mathrm{~km}$ or $10 \mathrm{~km}$ \\
Maximum Doppler range & $\pm 50 \mathrm{~Hz}$ \\
Clock standard & GPS signal or rubidium clock \\
\hline
\end{tabular}
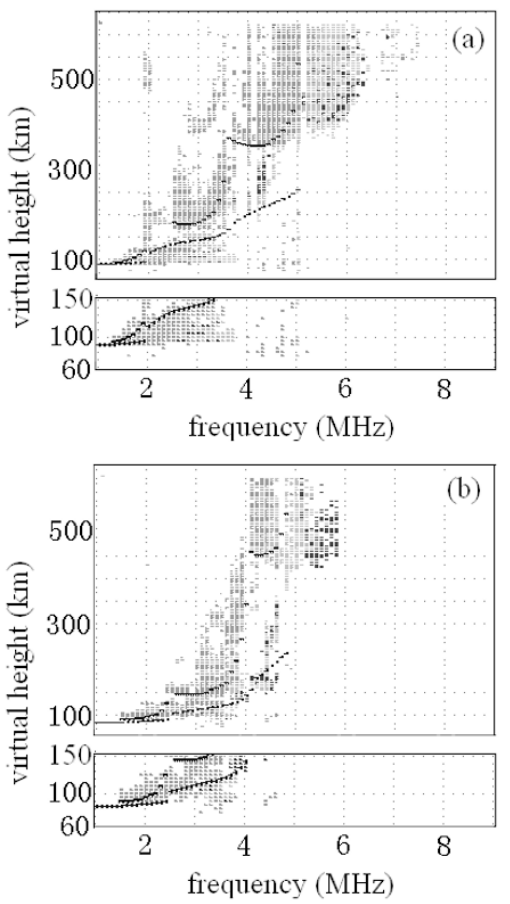

Fig. 1. Upper panels: Ionograms recorded by DPS-4 at 02:00 UT 06 Dec (a) and 05:00 UT 16 Dec (b) 1996, respectively. Bottom panels: Corresponding magnified ionograms trace in lower ionosphere (60-150 $\mathrm{km})$

dicated by the relationship between the frequency of radio pulse emitted upward and the virtual height of echoes reflected from the ionosphere. Figures 1 and 2 present irregular E and Es layers observed at Zhongshan Station. Upper panels show ionograms recorded by DPS-4, while bottom panels show corresponding magnified ionograms trace in lower ionosphere $(60-150 \mathrm{~km})$ respectively. The ionograms in Fig. 1 show irregular E and Es layers in solar active periods, while those in Fig. 2 show the phenomena in solar quiet periods. The virtual height of irregular E and Es layers is about $80-100 \mathrm{~km}$, much lower than the normal height
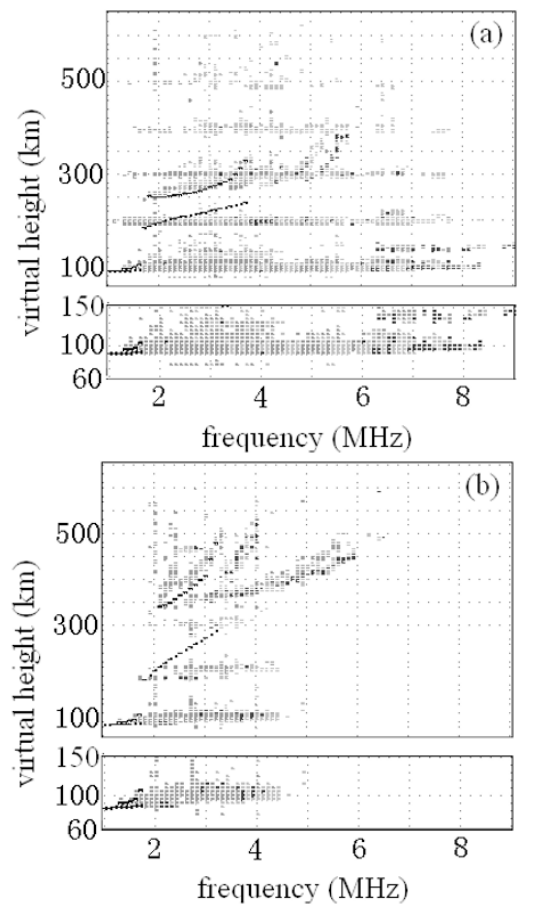

Fig. 2. Upper panels: Ionograms recorded by DPS-4 at 20:00 UT 24 Feb (a) and 21:00 UT 24 Feb (b) 2001, respectively. Bottom panels: Corresponding magnified ionograms trace in lower ionosphere (60-150 $\mathrm{km})$.

observed at mid- and low-latitude, besides the phenomena occur only at local summer. The virtual height is lower at local summer than that in winter, which is shown in Fig. 3. The monthly median values of Es layers vary with time at Zhongshan Station, Antarctica in 1995 and 2002. The solid and dot lines stand for the values observed in December and July respectively. The height and season of occurring the strange phenomena are consistent with those of PMSE observed in Arctic (Liu et al., 2002), i.e. the phenomena occur at local summer and near mesopause.

According to ionograms and monthly median values 

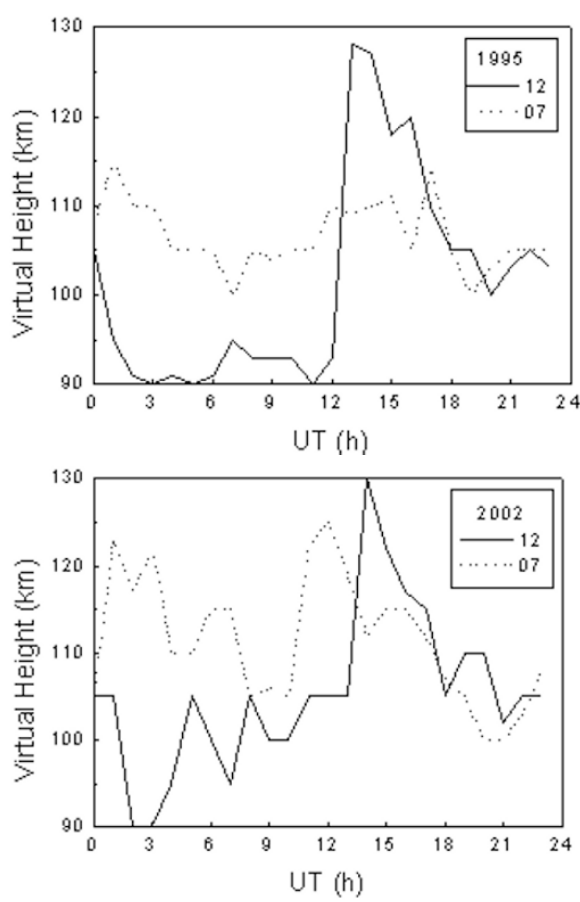

Fig. 3. The monthly median value of Es virtual height as function of time at Zhongshan Station, Antarctica in 1995 and 2002. The solid and dot lines stand for the values observed in December and July respectively.

from 1995 to 2002, one finds that most virtual height of Es layer are less than or equal to $90 \mathrm{~km}$ and the phenomena mainly occur in October, November, December, January and February every year. From October, the occurrence rate gradually increases then slowly reduces, and keeps a stable peak in December and January. This kind of irregular Es layer at Zhongshan Station may be called PMSE-like or PMSE-Es because it happens to appear in mesopause at local summer, i.e. the coldest time in the southern hemisphere at the same time.

Based on above observational phenomena and experimental results in Arctic, one can identify the PMSE-Es phenomena according to the following two conditions:

1) The virtual height of Es layer is less than or equal to $90 \mathrm{~km}$,

2) The virtual height of Es layer is less than or equal to the virtual height of normal E layer.

The first condition determines the occurrence rate of irregular Es layer in mesopause. The second removes the possible influence of normal $E$ layer. One finds if the data used in this paper satisfy the first condition, nearly all the corresponding virtual heights of Es layer are less than or equal to the corresponding virtual height of normal E layer at the same time. The statistical analysis as follows will mainly base on the virtual height of Es layer.

\section{Variational Rules of PMSE-Es at Zhongshan Station, Antarctica}

The occurrence rate of PMSE has its own regular variational rules, such as diurnal variation, semi-diurnal variation, seasonal variation, and solar activity secular variation etc. In comparison with PMSE variational rules, the varia-
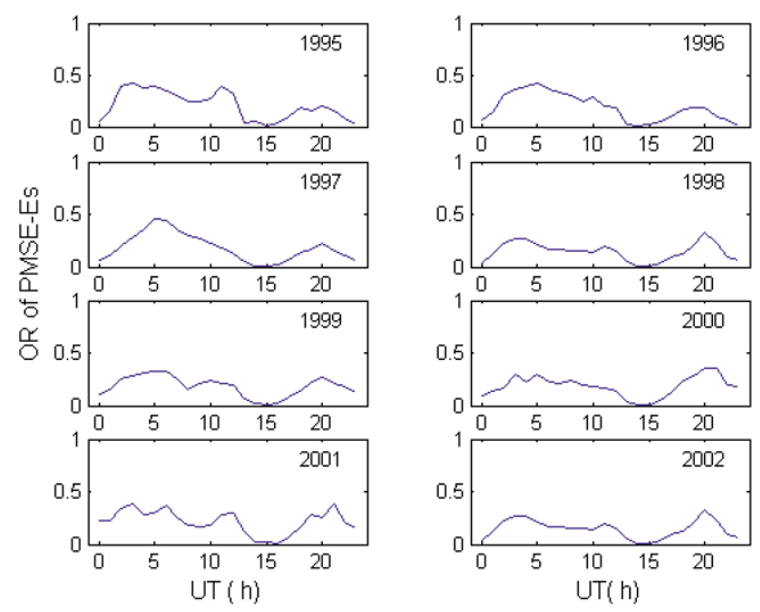

Fig. 4. Diurnal and semidiurnal variations of PMSE-Es occurrence rate during 1995-2002. OR stands for occurrence rate. The $x$-axis and $y$-axis stand for universal time (UT) and mean occurrence rate of PMSE-Es in five months (from October to February) respectively.

tional rules of PMSE-Es are studied at Zhongshan Station, Antarctica.

\subsection{The diurnal and semidiurnal variations of PMSE- Es}

Occurrence rates of PMSE have some rules by summing up the experimental results. The diurnal variation of PMSE has a marked semidiurnal character with a prominent minimum around 19:00-22:00 UT and maximum around 12:0013:00 UT observed by the Esrange MST radar (ESRAD) located at Esrange $\left(67^{\circ} 56^{\prime} \mathrm{N}, 21^{\circ} 04^{\prime} \mathrm{E}\right.$. $\mathrm{LT}=\mathrm{UT}+1$ hours $)$. These maxima and minima are stable through the whole season. Secondary maximum might occur in the early morning, but it is not so stable (Thomas, 1996; Bremer et al., 1996; Barabash, 2004).

The research about occurrence rate is carried out based on the data of irregular Es layer recorded once an hour with DPS-4 from 1995 to 2002 . The DPS-4 started to work in February 1995, so the data in January 1996 are replaced with those in January 1997.

The following analysis will be carried out during the lower solar quiet years (1995-1998) and the higher solar activity years (1999-2002) respectively. During the former years, geomagnetic activity is relatively tranquil and the ionosphere is less influenced by precipitating electrons. During the latter years, geomagnetic activity is relatively active and ionosphere is easy to suffer complicated perturbation. Then more complex situations will occur during the higher solar activity years.

According to the characteristics of monthly reportable form, the ratio of hours when PMSE-Es exists to the corresponding total observational hours is taken as occurrence rate of PMSE-Es.

Occurrence rate of PMSE-Es is analyzed from October to February in eight years. The mean occurrence rate of PMSE-Es in five months from 1995 to 2002 respectively are given in Fig. 4. The $x$-axis and $y$-axis stand for universal time (UT) and mean occurrence rate of PMSE-Es in five months, respectively. In lower solar activity year, the maximum of PMSE-Es occurrence rate reaches $40 \%$ at 05:00 


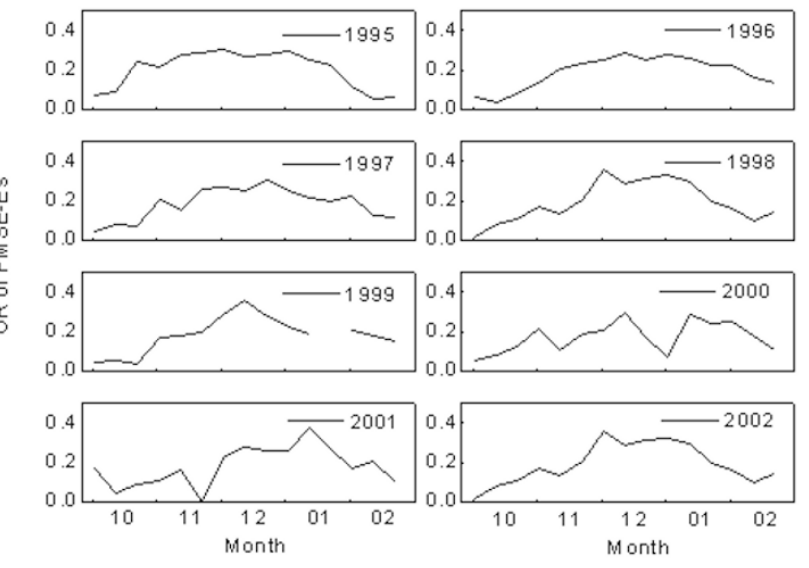

Fig. 5. Seasonal variation of the PMSE-Es occurrence rate during the years 1995-2002. OR stands for occurrence rate. The $x$-axis and $y$-axis stand for months (each month is separated into three parts) and mean occurrence rate of PMSE-Es respectively.

UT, and inferior maximum is $20 \%$ at 20:00 UT. The minimum occurs at 15:00 UT when the PMSE-Es nearly vanish. Though the peak value of PMSE-Es occurrence rate does not obviously change in higher solar activity year, the positions of the two-peak values exchange and the occurrence rate reduces.

The explanations of the PMSE semidiural variation include tidal temperature changes and temperature induced ice-aerosol modulations. The peak value of PMSE usually occurs at 11:00-13:00 LT, but the peak value of PMSE-Es occur at 9:00-11:00 LT. Since Zhongshan Station lies in special situation, many factors will affect PMSE-Es, such as tide and precipitating particles etc. Precipitating particles may play more important role there.

\subsection{The seasonal variations of PMSE-Es}

As already evidence of the pioneer work by Ecklund and Balsley (Ecklund and Balsley, 1981), PMSE reveal a pronounced seasonal variation. The main characteristics are that the steep increase during end of May/beginning of June, rather high level approaches $90 \%$ in the middle of June until the middle/end of July, and a gradually decrease during August (Bremer et al., 2003). The observations are in general agreement with independent observations from different radars located at almost the same geographical latitude (Balsley and Huaman, 1997; Kirkwood et al., 1998).

The seasonal variations of PMSE-Es are also investigated with above two conditions by taking ten days' data as a unit cell. Figure 5 represents the seasonal variations of PMSEEs in from 1995 to 2002 respectively. Because the occurrence rate of PMSE-Es of the other months approaches zero, only five months' data from October to February are used in the figure. The occurrence rate of PMSE-Es at Zhongshan Station in Fig. 5 is very similar to the results observed in Arctic.

Since the data in 1999 and 2001 being incomplete, some data in the fourth and sixth chart in Fig. 5 are empty. Figure 5 shows a pronounced seasonal variation of PMSE-Es: PMSE-Es begin to appear in October, gradually increase, then reach Maximum in November and keep stable to the end of January, finally drop fast. There are some differ- ences about occurence rate between PMSE-Es and PMSE observed in Arctic.

Another characteristics can also be obtained from Fig. 5. Occurrence rate of PMSE-Es is much more stable in lower solar activity period than in higher period. Occurrence rate of PMSE-Es experiences undulation even during the peak time. The possible reason is that the ionosphere is extremely easy to undergo the effects of various dynamical processes affecting the occurrence rate of PMSE-Es in lower solar activity period.

\section{Diurnal and Semidiurnal Variations Analyzed with Auroral Oval Diagram}

\subsection{The discrepancies of diurnal and semidiurnal vari-} ations

Some obviously different characteristics are got by comparing the results observed at Esrange, Arctic with those at Zhongshan Station, Antarctica. The occurrence rates of PMSE and PMSE-Es have some differences at multi-scales, such as diurnal, semi-diurnal and seasonal variation etc. Occurrence rate of PMSE-Es has two maximal peak values that the former is about four hours earlier than that of PMSE. The minimum appears at about 15:00 UT.

After comparing the geomagnetic latitudes of the two stations mentioned above with positions of the auroral oval, the discrepancies can be explained by quoting the diagram of auroral oval (Liou et al., 1997; Feldstein and Starkov, 1967). The Zhongshan Station begins to enter the auroral oval at about 13:00 UT (MLT15:00), ionosphere temperature rises with the heat of precipitating particles, and then PMSE-Es vanish with the electron temperature rising (Havnes et al., 2003). Zhongshan Station lies in the position where occurrence rate of aurora is relatively low from 01:00 to 11:00 UT, so the occurrence rate of PMSE-Es can keep a high value. Zhongshan Station stands in the outside of auroral oval since 18:00 UT, when the second maximum of PMSE-Es occurrence rate begins to appear.

While Esrange Station lies in the outside of auroral oval in the daytime, occurrence rate of PMSE can maintain a quite high value. After 18:00 UT Esrange Station starts to enter the auroral oval and PMSE vanishes. Once Esrange Station leaves the auroral ovel, PMSE starts to appear again.

Here the differences are only explained with ionosphere temperature affected by precipitating particles. In fact, the ionosphere in polar area is an extremely complex system and has many other influencing factors. Besides the primary factor we consider, other possible factors are worth considering too.

\subsection{The discrepancy of seasonal variation}

Though the seasonal variation rule of PMSE-Es occurrence rate has extremely similar characteristics with that of PMSE, the absolute value of occurrence rate has distinct differences. The differences can be understood in the following two aspects.

Firstly, the criteria of PMSE-Es come from scanned trace and virtual height of ionogram observed by DPS-4 without the support of echo intensity, so the minor deviation is inevitable. Many effects will affect the PMSE-Es, such as tide and precipitating particles. Besides the ionosphere is a dispersive medium, its diffusion properties vary with work- 
ing frequency. The measurement results may be different (Bremer et al., 1996).

Secondly, the data used in the paper are provided with the form of monthly reportable table. Time resolution of the data is not very high, because DPS-4 does not have the high time resolution like VHF radar which can continuously observe PMSE. Then different results may be gotten.

\section{Conclusions}

The data inferred DSP-4 at Zhongshan Station are analysed to study the irregular characteristics of the E and Es layers and two cirteria are proposed to study PMSE-Es. The results show that PMSE-like or PMSE-Es phenomena can be detected at MF and HF radar frequencies.

The statistical results show that the occurrence rate variations of PMSE-Es exhibit similarity to those of PMSE at multi-scales, such as seasonal, diurnal, and semidiurnal variation. Finally, the discrepancies between diurnal and semidiurnal variations are discussed with the diagram of auroral oval. The differences of seasonal variation between the Northern and Southern Hemisphere at between solar activity and quiet period are also illustrated.

Acknowledgments. This work was supported by the National Natural Science Foundation of China (No. 40310223) and the National Key Laboratory of Electromagnetic Environment, China Research Institute of Radiowave Propagation (CRIRP).

\section{References}

Balsley, B. B. and M. Huaman, On the relationship between seasonal occurrence of northern hemispheric polar mesosphere summer echoes and mean mesopause temperatures, J. Geophys. Res., 102, 2021-2024, 1997.

Barabash, V., Investigation of polar mesosphere summer echoes in northern Scandinavia, IRF Scientific Report 283., 2004.

Bremer, J., P. Hoffmann, A. Manson, C. Meek, R. Rüster, and W. Singer, PMSE observations at three different frequencies in northern Europe during summer 1994, Ann. Geophys., 14, 1317-1327, 1996.

Bremer, J., P. Hoffmann, R. Latteck, and W. Singer, Seasonal and long term variation of PMSE from VHF radar observations at Andenes, Norways, J. Geophys. Res., 108(D8), 8438, doi:10.1029/2002JD002369, 2003.

Cho, J. Y. N. and M. K. Kelly, Enhancement of thomson scatter by charged aerosols in the polar mesosphere: with a $1.29-\mathrm{GHz}$ radar, Geophys. Res. Lett., 19(11), 1097-1100, 1992.

Ecklund, W. L. and B. B. Balsley, Long-term observations of the Arctic mesosphere with the MST radar at Poker Flat Alaska, J. Geophys. Res., 86, 7775-7780, 1981.
Feldstein, Y. I. and G. V. Starkov, Dynamics of auroral belt and polar geomagnetic disturbance, Planet. Space Sci., 15, 209, 1967.

Havnes, O., C. La Hoz, and L. I. Næsheim, First observations of the PMSE overshoot effect and its use for investigation the conditions in the summer mesosphere, Geophys. Res. Lett., 30(23), 2229, doi:1029/2003GL018429, 2003.

Hosokawa, K., T. Ogawa, A. S. Yukimatu, N. Sato, and T. Iyemori, Statistics of antarctica mesospheric echoes observed with the SuperDARN Syowa radar, Geophys. Res. Lett., 31, L02106, doi:10.1029/ 2003GL018776, 2004.

Hosokawa, K., T. Ogawa, N. F. Arnold, M. Lester, N. Sato, and A. S. Yukimatu, Extraction of polar mesosphere summer echoes from SuperDARN data, Geophys. Res. Lett., 32, 10.1029/2005GL022788, 2005.

Karashtin, A. N., Y. V. Shlyugaev, V. I. Abramov, I. F. Belov, I. V. Berezin, V. V. Bychkov, E. B. Eryshev, and G. P. Komrakov, First HF radar measurements of summer mesopause echoes at SURA, Ann. Geophys., 15, 935-941, 1997.

Kirkwood, S., V. Barabash, P. Chilson, A. Rechou, K. Stebel, P. Espy, G. Witt, and T. Stegman, The 1997 pmse season-its relation to wind, temperature and water vapour, Geophys. Res. Lett., 25, 1867-1870, 1998.

Lee, C. C., J. Y. Liu, C. J. Pan, and C. H. Liu, Doppler velocities obtained by the EISCAT VHF and the dynasonde during the PMSE95 campaign, J. Atmos. Solar. Terr. Phys., 63, 193-199, 2001.

Liou, K., P. T. Newell, C. I. Meng, M. Brittnacher, and G. Parks, Synoptic auroral distribution: a survey using polar ultraviolet imagery, J. Geophys. Res., 102(A12), 27179-27206, 1997.

Liu, J. Y., C. J. Pan, and C. C. Lee, VHF radar and MF/HF dynasonde observations during polar mesosphere summer echoes conditions at EISCAT, Earth Planets Space, 54, 691-698, 2002.

Liu, R. Y., S. L. Qian, and L. S. He, Preliminary experimintal results about the digisonde portable sounder-4 at Zhongshan Station, Antarctica, Progress in Geophysics, 12(4), 109-118, 1997 (in Chinese).

Ogawa, T., N. Nishitani, H. Yamagishi, and A. A. Yukimatu, Upper mesosphere summer echoes detected with the Antarctica Syowa HF radar, Geophys. Res. Lett., 29(7), 10.1029/2001/GL014094, 2002.

Ogawa, T., N. F. Arnold, S. Kirkwood, N. Nishitani, and M. Lester, Finnland HF and Esrange MST radar observations of polar mesosphere summer echoes, Ann. Geophys., 21, 1047-1055, 2003.

Rapp, M. and F-J. Lübken, Polar mesosphere summer echoes (PMSE): review of observations and current understanding, Atmos. Chem. Phys., 4, 2601-2633, 2004.

Tereshchenko, V. D., E. B. Vasiliev, and V. A. Tereshchenko, The polar mesospheric MF echoes, "physics of auroral phenomena", Proc.XXV Annual Semina, Apatity., 118-121, 2002.

Thomas, G. E., Is the polar mesosphere the miner's canary of global change?, Adv. Space. Res., 18(3), 149-158, 1996.

H.-L. Li (e-mail: hailong703@163.com), J. Wu, R.-Y. Liu, and J.-Y. Huang 